\title{
A study of outcome of induction of labour with foley's balloon in previous LSCS cases
}

\section{Srinivas Krishna Jois*, Sunanda K. M.}

Department of Obstetrics and Gynecology, Bangalore Medical College and Research Institute, Bangalore, Karnataka, India

Received: 09 April 2017

Accepted: 17 April 2017

\section{*Correspondence:}

Dr. Srinivas Krishna Jois,

E-mail: srinivaskjois@gmail.com

Copyright: (C) the author(s), publisher and licensee Medip Academy. This is an open-access article distributed under the terms of the Creative Commons Attribution Non-Commercial License, which permits unrestricted non-commercial use, distribution, and reproduction in any medium, provided the original work is properly cited.

\section{ABSTRACT}

Background: Induction of labour in a scarred uterus is a controversial topic in Obstetric practice, but in carefully selected and monitored cases never the less the outcome is gratifying. When the baby is non-salvageable, or in cases of IUFD, it is always desirable to achieve a vaginal delivery. Many of the professional organizations recommend induction of labour in previous LSCS. Thus, this study was done to evaluate the success rate, determinants of failure and complications of induction of labour with foley's catheter in patients with previous 1 LSCS.

Methods: 62 patients were recruited over a period of 1 year and studied at Vani Vilas Hospital, Bangalore Medical College and Research Institute, all with previous 1 LSCS. $34 \%$ of them were with past h/o 1 or more vaginal delivery. $8 \%$ were term pregnancies, 64\% were between 28-32 weeks. Induction was done for IUFD in 56\% and, HDP warranting termination in $44 \%$. Induction done with Foley's catheter, expulsion of catheter with filled bulb and uterine contraction initiation was taken as successful induction. The patient profile in cases of failure was noted.

Results: $83 \%$ was the success rate for induction out of which $30 \%$ cases required additional PGE2 gel. Oxytocin and ARM alone or together were used for augmentation in $90 \%$ cases. Induction to foley's expulsion average duration was 14 hours. Post expulsion delivery happened at an average time interval of 5 hours. One patient had rupture uterus during the course of augmentation.

Conclusions: Induction can be done safely in carefully selected cases of previous LSCS with Foley's Balloon.

Keywords: Foley's induction, Failed induction, Labour induction in previous cesarean

\section{INTRODUCTION}

TOLAC (Trial of labour after cesarean) has a short history of around 50 years and the option became available for the pregnant mothers only after the obstetricians started questioning Craigin's statement that once a cesarean always a cesarean. The literature on this topic of obstetrics compared to other topics of OBG is not that abundant, conclusions are not that robust. With the opening of option of vaginal delivery in a case of previous cesarean section, the need for induction of labour has surfaced. Though many choices exist for induction of labour pharmacological methods have the highest success rate. An ideal inducing agent needs to have a short induction delivery interval, least incidence of cesarean section and with no adverse effects for the mother or the baby. So, it is necessary to find the best possible agent to induce labour especially while dealing with a scarred uterus. Most of the professional societies like ACOG, RCOG, SOGC. ${ }^{1-3}$ not recommending the use of pharmacological methods for induction in a scarred uterus, the safest option available is mechanical method alone.

Pharmacological methods using oxytocin alone for induction is no longer the best method available as the 
induction delivery is abnormally prolonged. ${ }^{4}$ Significant improvement in Bishop's score is achieved by PGE2 intra cervical gel compared to oxytocin. ${ }^{5}$ Membrane rupture alone is not recommended by WHO for induction of labour. In IUFD with prev LSCS, mifespristone and either PGE2 or PGE1 may be used. ${ }^{6}$

Success of a carefully selected case for TOLAC is to the tune of $75-85 \%$ which has a tremendous influence on the future obstetric career of the woman. ${ }^{7}$ The risk of rupture is about $0.5 \%$. ACOG warns against the use of Misoprostol for Prev. LSCS where as NICE guidelines recommend the use of PGE2 gel on a scarred uterus for induction. ${ }^{8}$ In 2001, Lydon-Rochelle et al demonstrated a 3 -fold increase in the risk for uterine rupture when comparing patients induced with PGs with those induced with oxytocin. ${ }^{9}$

In the 2004 study by Landon et al, this effect of PG induction versus other means was smaller-less than (uterine rupture) 2-fold. ${ }^{10}$ For inducing labour for a lethal anomaly or intrauterine fetal demise, ballon catheter induction has been recommended. There is insufficient information available from RCTs on which to base clinical decisions regarding the optimal method of induction of labour in women with a prior caesarean birth. ${ }^{11}$ PROBAAT trial concludes that induction of labour with a Foley catheter is as effective as induction with intravaginal PGE2 gel, with fewer side effects to both mother and the fetus. ${ }^{12}$

The need for induction of labour in a pregnant woman may arise for maternal reasons, like any maternal disease that is aggravated by pregnancy and endangers the life of the mother (e.g. Severe pre-eclampsia/eclampsia) or for fetal reasons like compromised baby, intrauterine fetal demise, lethal congenital anomaly, prolonged pregnancy etc., In a previously scarred uterus, option of vaginal delivery needs to be strongly considered especially when a favourable fetal outcome is not guaranteed in situations like cases of severe preeclampsia and eclampsia in a preterm pregnant patient, women with intrauterine fetal demise etc. ${ }^{13}$

Best method, efficacy and safety of cervical ripening and/or labor induction in these women has not been established. Hence, this study was undertaken in patients with previous one lower segment cesarean section with a non-salvageable baby (in our existing setup) and the determinants of success of mechanical method of induction using a foley's bulb and its effect on the maternal and fetal outcome were studied.

The objectives of this study were to determine the success rate of induction with foley's balloon in cases with previous 1 cesarean section. To identify the determinants of success and failure of induction of labour with foley's balloon in previous 1 cesarean section and to evaluate the complications of foley's induction in previous 1 cesarean section.

\section{METHODS}

It was a prospective analytical observational study done over a period of 12 months at Vani Vilas Hospital, attached to Bangalore medical college and research Institute Bangalore, India.

All patients with history of previous one lower segment cesarean section (verified by records regarding the type of cesarean) with properly defined indications for termination of pregnancy were included in the study.

\section{Inclusion criteria}

All Multigravida with $>28$ weeks and $<34$ weeks of gestation with previous $1 \mathrm{LSCS}$, for women with $>34$ weeks of gestation with previous 1 LSCS with nonrecurrent indications.

\section{Exclusion criteria}

>1LSCS beyond 34 weeks with recurrent indications, patients not consenting for vaginal trial, Eclampsia, age >40years, salvageable baby with maternal co morbid conditions, women presenting in labour, obstetric indications for LSCS, active vaginal infection, prolonged PROM, mal presentations, APH with maternal compromise, IUDs with coagulation defects, salvageable baby, other systemic disorders like cardiac, renal etc., short women $<140 \mathrm{cms}$, macrosomia and postdated pregnancy. Most of the established determinants of failure of induction were avoided.

A detailed history regarding the age, parity, duration of amenorrhoea, booked/unbooked, details of previous cesarean, duration from the past cesarean, its outcome, post-operative period, co morbidities were recorded. General examination, systemic examination and obstetric examination were done. All the routine investigations, obstetric ultrasound was done. Definitive indication for termination of pregnancy was established in all the patients and non-salvageability of the baby was also affirmed.

Informed consent for induction was obtained.

Under all aseptic precautions, a no 16 foley's catheter was introduced into the extra amniotic space through the cervix and the bulb was inflated with $50 \mathrm{ml}$ distilled water, the catheter was snugly fit on to the internal os by giving traction and by maintaining the same traction, the catheter was tied to the thigh. (Hanging a weight was done in patients who could not be allowed to move).

Patients were observed for 12-24 hours which was arbitrarily selected (12hours in cases of hypertensive disorders of pregnancy, 24 hours in cases with intrauterine fetal demise without hypertensive disorders), by watching for uterine activity. Vaginal examination was done once in 6 hours. Additional methods for 
induction were used if induction was not successful in 12-24 hours. If the catheter got expelled, then if required, ARM and or oxytocin were used for augmentation. Patient was monitored as in any other case of TOLAC.

Their age, parity, duration of gestation, indication for termination, duration from prev LSCS, Other co morbidities, estimated fetal weight, presence of infection, were tabulated. After induction, induction to catheter expulsion time and expulsion to delivery interval were noted in all cases. Any deviation from normalcy suggesting maternal adverse events, decision was immediately taken to proceed with emergency cesarean delivery. Complications including failure of induction, uterine rupture, need for ICU admission, need for hysterectomy, infections, PPH, etc were noted.

\section{Statistical analysis}

The Statistical Package Graph pad Instat was used for data entry and analysis. Fisher's test/chi-square test was used to calculate two-tailed (also called two-sided) $\mathrm{P}$ values for all the categorical data. A $p$ value of $<0.050$ was deemed to be statistically significant.

\section{RESULTS}

Out of the 62 patients recruited for the study, 51 patients had a successful vaginal delivery with labour induction. Youngest woman was 21 years and the oldest one was 35 years old.The failure documented as per the age group is shown in Table 1.

Table 1: Age group and failure of induction.

\begin{tabular}{|lll|}
\hline Age & No & Failure \\
\hline $20-25$ & 19 & 02 \\
\hline $25-30$ & 34 & 05 \\
\hline $30-40$ & 09 & 04 \\
\hline
\end{tabular}

41 patients $(66 \%)$ were with no previous vaginal deliveries and pregnant for the 2nd time with 6 of them showing failure, 15 (24\%) were with history of 1 vaginal delivery with 3 failures and $6(10 \%)$ had history of 2 previous vaginal deliveries with 2 of them showing failure. This is shown in Table 2 .

Table 2: Order of pregnancy and failure.

\begin{tabular}{|lll|}
\hline Order of pregnancy & Number & Failure \\
\hline G2 & 41 & 06 \\
\hline G3 & 15 & 03 \\
\hline G4 & 06 & 02 \\
\hline
\end{tabular}

2 of the patients were less than $135 \mathrm{cms}$ in height of whom 1 patient had a successful induction. Amongst the women with normal height 10 of them did not show response to induction (Table 3 ).
Table 3: Height of the patients and success of induction.

\begin{tabular}{|lll|} 
Height & Success & Failure \\
\hline Normal & 49 & 10 \\
\hline Short & 2 & 1 \\
\hline
\end{tabular}

2 women weighing more than $75 \mathrm{kgs}$ did not respond to induction and amongst the ones with $<75 \mathrm{kgs} 11$ women showed failure out of 60 (Table 4).

Table 4: Weight and success of induction.

\begin{tabular}{|lll|}
\hline Weight & Success & Failure \\
\hline Normal & 49 & 9 \\
\hline$>75 \mathrm{Kgs}$ & 2 & 2 \\
\hline
\end{tabular}

Women aged $>30$ the success rate was only $55 \%$ (5 out of 9) whereas <30years women the success rate was $87 \%$ (46 out of 53) (Table 5).

Table 5: Influence of age on success of induction.

\begin{tabular}{|ll|l|}
\hline Age in years & Success & Failure \\
\hline$<30$ & 46 & 7 \\
\hline$>30$ & 5 & 4 \\
\hline
\end{tabular}

Table 6 shows a tabulation of the established predictors of failure and the outcome in the present study. $33 \%$ was the failure in short women, $50 \%$ in obese women and $45 \%$ in women aged $>30$ years.

Table 6: Predictors of failure and the outcome.

\begin{tabular}{|ll|}
\hline Predictors & Failure \\
\hline Short height & $1 / 3$ \\
\hline Obesity $>75 \mathrm{Kgs}$ & $2 / 4$ \\
\hline Age $>30$ & $4 / 9$ \\
\hline Indication & \\
\hline Non-recurrent & $9 / 39$ \\
\hline Recurrent & $2 / 23$ \\
\hline Gest age & \\
\hline Term & $3 / 5$ \\
\hline $32-17$ weeks & $6 / 17$ \\
\hline $28-32$ weeks & $2 / 40$ \\
\hline Prev LSCS & 10 \\
\hline$>18 m$ ths & $10 / 51$ \\
\hline$<18 m$ ths & $1 / 11$ \\
\hline Prev vag delivery & \\
\hline yes & $0 / 21$ \\
\hline no & $11 / 41$ \\
\hline
\end{tabular}

Analysis of indications for previous cesarean and present outcome, recurrent indications showed a $9 \%$ failure and $23 \%$ failure for non-recurrent indications (All of the recurrent indications patients were $<34$ weeks gestation).

$60 \%$ was the failure in term pregnancies, $35 \%$ in pregnancies between $32-37$ weeks and $5 \%$ in pregnancies 
$<32$ weeks. If the previous section was done within the past 18 months the success was $90 \%$ and for $>18$ months the failure was $19 \%$.

All the failures were in patients without a single past vaginal delivery, that is to say that previous vaginal delivery was a strong predictor for success of induction (all 21 patients had successful induction)

Table 7: Indications for labour induction.

\begin{tabular}{|lll|}
\hline Gestational age & $\begin{array}{l}\text { Severe PE/Impending } \\
\text { eclampsia }\end{array}$ & IUFD \\
\hline 28-32 weeks- 40 & 19 & 21 \\
\hline 32-36 weeks-17 & 08 & 09 \\
\hline Term-05 & 00 & 05 \\
\hline
\end{tabular}

Table 7 shows the list of indications for induction of labour at different gestational age. $64 \%$ of them were between 28-32 weeks of gestation, $27 \%$ between $32-27$ weeks of gestation and the remaining $9 \%$ were term pregnancies. $43 \%$ of them were induced for severe preeclampsia, and $57 \%$ for IUFD.

All the term pregnancies were in this IUFD group and none with hypertension.

GDM was an associated co morbidity in 11 patients, Anaemia in 19 of them.

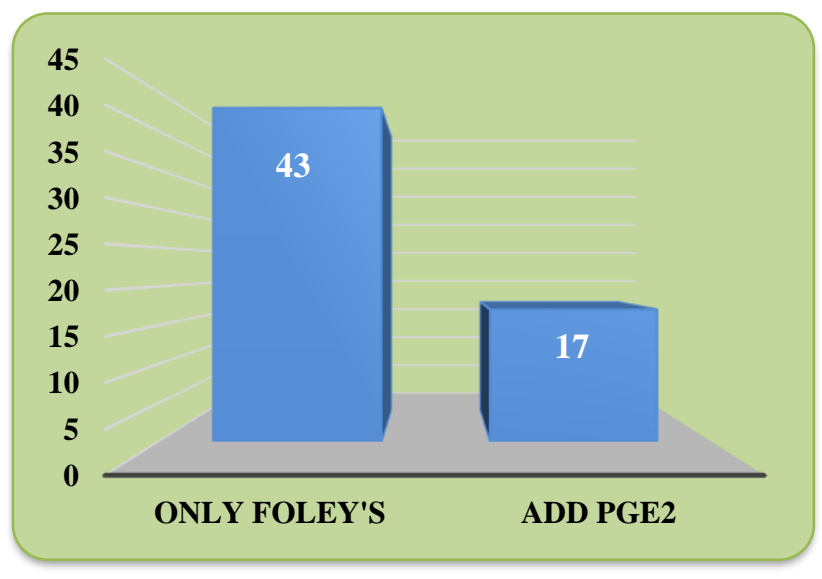

Figure 3: Induction methods used.

When the uterine contraction initiation was not achieved in 12-24 hours PGE2 gel was used as an additional method in 17 cases (Figure 1).

Used Oxytocin in 48 cases for augmentation and ARM in 30 (All were HDP cases and cases of IUD due to abruption) cases (Figure 2).

Insertion to expulsion of the catheter and expulsion to delivery intervals in the study was around 12 hours and 4 hours respectively.

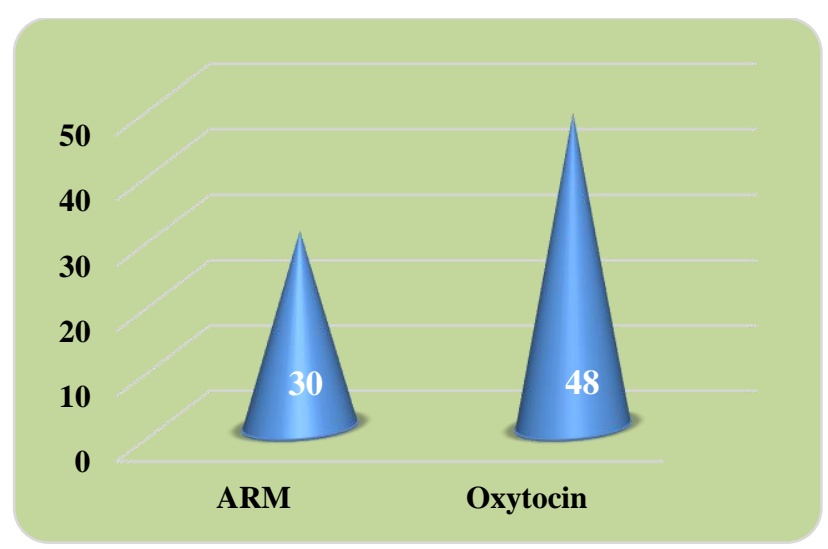

Figure 2: Augmentation methods used and their frequency.

The following outcomes/complications were encountered in our patients.

- Failed induction in 11 cases, none had chorioamnionitis. PPH was encountered in 3 cases, all the three were cases of abruption and were managed medically.

- 1 case of scar rupture was encountered which was diagnosed during the late 1st stage during oxytocin augmentation and was managed conservatively by laparotomy and scar repair. This was a case of IUFD at term with no other co morbidity.

- In 2 cases, there was Puerperal sepsis-Grade 1 which responded to broad spectrum antibiotics. Hospital stay duration least was 3 days, and maximum was 8 days prolonged stay was not directly attributable to Foley's, but were due to hypertension, abruption, anaemia and other co morbidities.

- 4 patients required ICU admission all for severe, with favourable outcome and none required Pre eclampsia, all ventilation. All were admitted to ICU in the later part of the established labour or in the post-partum period.

- $\quad$ Blood and product transfusions was required for 17 patients again not attributable to induction method.

\section{DISCUSSION}

Studies on labour induction in a scarred uterus, a challenging situation are yet to come out with clear cut recommendations and the best method of induction. But however various studies including largescale multicentric studies are trying to prove the safety of labour induction in previous LSCS. ACOG clearly not recommending induction in a uterus with two previous cesarean scars, most of the studies have been done on patients with previous one scar but recommends that induction should be an option for women willing for TOLAC. ${ }^{14}$

Our study with a moderate number of patients (62) has demonstrated that induction with mechanical methods is quite safe in previous 1 LSCS where we encountered 1 case of rupture (1.6\%). Decker et al 2010 concluded that 
the risk of rupture with induction of labour was $0.54 \%$ for oxytocin alone, $0.68 \%$ for prostaglandin alone, $0.63 \%$ without either and $0.88 \%$ when they were combined. ${ }^{15} \mathrm{~A}$ US study (Ouzouian et al) found no difference in rupture rates between spontaneous and induced labours but found a significantly greater vaginal birth rate following spontaneous labour. ${ }^{16}$ Contrary to this, a study by Fitzpatrick et al showed an increased risk with induction. ${ }^{17}$ In 2000, a Norwegian study on 18794 patients with previous CS, resulted in 94 uterine ruptures amounting to $0.5 \%$. They recommend that if needed, mechanical induction should be used instead of medical induction by prostaglandins. ${ }^{18}$ Most of the demographic data of the present study is similar to a study by Hazel Gonsalves et al. ${ }^{19}$ The number of women with history of vaginal delivery, age group of the patients, BMI are similar to our study, but their study involves mostly term patient's contrary to ours which has mostly pre term patients with obstetric complications. Younger age of the patients and previous vaginal delivery were the statistically significant determinants in their study on the success of induction whereas in our study, younger age of the patient, lesser gestational age and history of previous vaginal delivery showed statistical significance as the determinants of successful induction. Foley's balloon has been recommended by some studies as a very safe method in unscarred uterus. ${ }^{20}$ With 255 patients induced with foley's balloon with previous cesarean section, there was no increased rupture demonstrated in another study by Bujold et al. ${ }^{21}$

Table 8 shows statistical significance of some of the predictors of successful induction and Table 9 shows a comparison of our study with other similar studies. Presents study has certain limitations. It does not include fetal outcome as a parameter as the indication for inclusion in the study in most of the cases is IUFD (56\%) or HDP $(44 \%)$ with forced preterm delivery. Number of patients is relatively small. It has not included many pregnant mothers at term which can have a major influence on the success of induction. No comparative study has been done with other methods of induction. Randomization and prospective trials are more conclusive. Complications may have been biased because of maternal co morbidities.

\section{CONCLUSION}

Induction of labour is a safe procedure in previous 1 LSCS patients and the agent of choice is yet to be established. But of the available agents mechanical method is a safe method that may be used in selected cases and success may be achieved if the predictors of success are looked into amongst the subjects.

\section{ACKNOWLEDGEMENTS}

The authors would like to acknowledge the support by Dr K V Malini, the Head of the department of Obstetrics and Gynaecology for her support during the study.
Funding: No funding sources

Conflict of interest: None declared

Ethical approval: The study was approved by the Institutional Ethics Committee

\section{REFERENCES}

1. ACOG. Vaginal birth after cesarean (VBAC): resource overview. Available from: http://www.acog.org/Womens-Health/Vaginal-BirthAfter-Cesarean-VBAC

2. RCOG. Birth after previous caesarean birth. Greentop Guideline No. 45, October 2015. Available from: https://www.rcog.org.uk/globalassets/documents/gui delines/gtg_45.pdf

3. SOGC clinical practice guidelines. Guidelines for vaginal birth after previous caesarean birth. Available from: https://sogc.org/wpcontent/uploads/2013/01/155E-CPG-

February2005.pdf

4. ACOG Practice Bulletiin. Clinical management guidelines for obstetrician-gynecologist. No 107, August 2009. Available from: https://www.mnhospitals.org/Portals/0/Documents/p atientsafety/Perinatal/acog-practice_bulletin_107_2009.pdf

5. Ulmsten U, Wingerup L, Belfrage P, Ekman G, Wiqvist N. Intracervical application of prostaglandin gel for induction of term labor. Obstet Gynecol. 1982;59(3):336-9.

6. RCOG green top guidelines, late intrauterine fetal death and stillbirth; 2010:55.

7. Behrens O1, Goeschen K, Jakob H, Kauffels W. Induced labor with prostaglandin E2 gel after previous cesarean section. Geburtshilfe Frauenheilkd. 1994;54(3):144-50.

8. Induction of Labor (August 2009, Reaffirmed 2016) (Replaces Practice Bulletin Number 10, November 1999; Committee Opinion Number 228, November 1999; Committee Opinion Number 248, December 2000; Committee Opinion Number 283, May 2003).

9. Rochelle ML, Holt VL, Easterling TR. Risk of uterine rupture during labor among women with a prior cesarean delivery. N Engl J Med. 2001;345:3-8

10. Landon MB, Hauth JC, Leveno KJ, Spong CY, Leindecker S, Varner MW et al. Maternal and perinatal outcomes associated with a trial of labor after prior cesarean delivery. $\mathrm{N}$ Engl $\mathrm{J}$ Med. 2004;351:2581-9.

11. Jozwiak M1, Dodd JM. Methods of term labour induction for women with a previous caesarean section. Cochrane Database Syst Rev. 2013;(3):CD009792.

12. Jozwiak M, Rengerink K, Benthem M, van Beek E, Dijksterhuis M, de Graaf I et al. Foley catheter versus vaginal prostaglandin E2 gel for induction of labour at term (PROBAAT trial): an open-label, randomised controlled trial. The Lancet. 2011;378(9809):2095-103. 
13. Hutto SL. Induction of labor: indications, methods, challenges and outcomes. Available from: https://www.obgyn.umn.edu/sites/obgyn.umn.edu/fil es/induction-of-labor.pdf

14. American College of Obstetricians and Gynecologists. ACOG practice bulletin no. 115: Vaginal birth after previous cesarean delivery. Obstet Gynecol. 2010;116:450-63.

15. Dekker GA, Chan A, Luke CG, Priest K, Riley M, Halliday $\mathbf{J}$ et al. Risk of uterine rupture in Australian women attempting vaginal birth after one prior caesarean section: a retrospective population-based cohort study. BJOG. 2010;117(11):1358-65.

16. Ouzounian JG, Miller DA, Hiebert CJ, Battista LR, Lee RH. Vaginal birth after cesarean section: risk of uterine rupture with labor induction. Am J Perinatol. 2011;28(8):593-6.

17. Fitzpatrick KE, Kurinczuk JJ, Alfirevic Z, Spark P, Brocklehurst $\mathrm{P}$, Knight $\mathrm{M}$. Uterine rupture by intended mode of delivery in the UK: A national case-control study. PLoS Med. 2012;9(3):e1001184.
18. Al-Zirqi I, Stray-Pedersen B, Forsén L, Vangen S. Uterine rupture after previous caesarean section. BJOG. 2010;117(7):809-20.

19. Gonsalves H, Al-Riyami N, Al-Dughaishi T, Gowri V, Al-Azri M, Salahuddin A. Use of intracervical foley catheter for induction of labour in cases of previous caesarean section experience of a single tertiary centre in Oman. Sultan Qaboos University Med J. 2016;16(4):445-50.

20. Prager M, Eneroth-Grimfors E, Edlund M, Marions L. A randomised controlled trial of intravaginal dinoprostone, intravaginal misoprostol and transcervical balloon catheter for labour induction. BJOG 2008;115:1443-50.

21. Bujold E, Blackwell SC, Gauthier RJ. Cervical ripening with transcervical foley catheter and the risk of uterine rupture. Obstet Gynecol. 2004;103:18-23.

Cite this article as: Jois SK, Sunanda KM. A study of outcome of induction of labour with foley's balloon in previous LSCS cases. Int J Reprod Contracept Obstet Gynecol 2017;6:2067-72. 